This item was submitted to Loughborough's Research Repository by the author.

Items in Figshare are protected by copyright, with all rights reserved, unless otherwise indicated.

\title{
Using feedback control engineering for analyzing and designing an effective lecturing model
}

PLEASE CITE THE PUBLISHED VERSION

PUBLISHER

(C) IEEE

VERSION

VoR (Version of Record)

\section{LICENCE}

CC BY-NC-ND 4.0

\section{REPOSITORY RECORD}

Abdulwahed, Mahmoud, Zoltan K. Nagy, and Richard E. Blanchard. 2009. "Using Feedback Control Engineering for Analyzing and Designing an Effective Lecturing Model”. figshare. https://hdl.handle.net/2134/4934. 
This item was submitted to Loughborough's Institutional Repository (https://dspace.lboro.ac.uk/) by the author and is made available under the following Creative Commons Licence conditions.

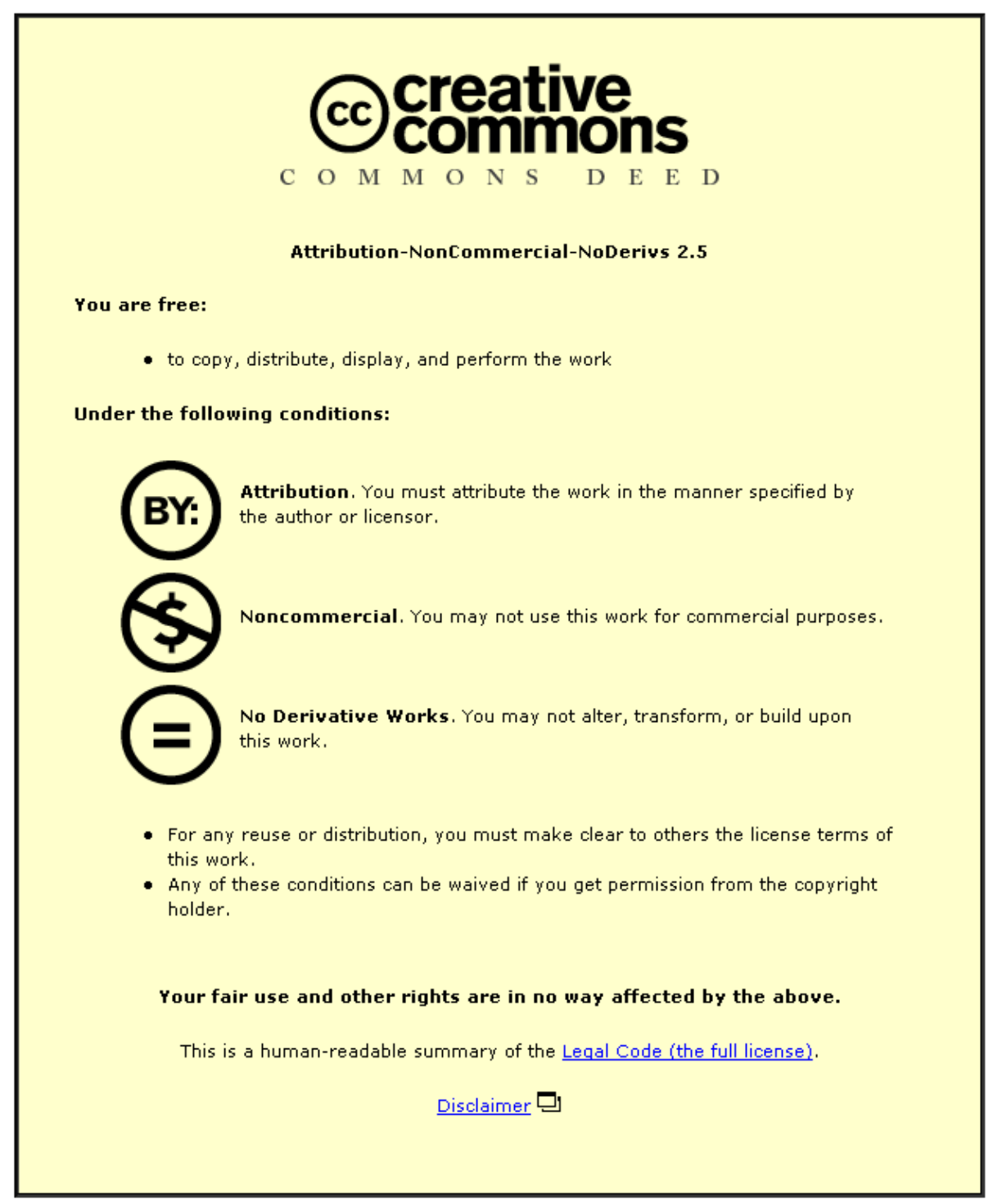

For the full text of this licence, please go to: http://creativecommons.org/licenses/by-nc-nd/2.5/ 


\title{
Using Feedback Control Engineering for Analyzing and Designing an Effective Lecturing Model
}

\author{
Mahmoud Abdulwahed, Zoltan K Nagy, Richard Blanchard \\ Loughborough University, m.abdulwahed@lboro.ac.uk, z.k.nagy@lboro.ac.uk, r.e.blanchard@lboro.ac.uk
}

\begin{abstract}
Control theory has seldom been used as an analytical tool in pedagogical research for modeling, analyzing or designing effective educational processes, despite its proven benefits in other social sciences, especially economics and finance. In this paper, we use the elements of open-loop and closed-loop feedback systems for evaluating two modes of teaching and lecturing. The first is the open-loop lecturing mode, which still dominates in many European universities, whereas the second is the so-called closed-loop lecturing with feedback and reflection. We provide mathematical models for both modes and apply control engineering techniques and tools to analyze the properties of the two lecturing modes. It is shown that the learning and information retention dynamics differs considerably between the two modes. Furthermore, we show how the closed-loop lecturing mode supersedes the open-loop lecturing mode. The simulation results demonstrate that with lecturing improved higher educational performance requires continuous feedback and reflection.
\end{abstract}

Index Terms - Educational design, pedagogical feedback control, constructivism.

\section{INTRODUCTION}

Traditional lecturing models have, in the main, adopted an open-loop mode in which the teacher spends a lecture, lasting approximately an hour, presenting material to the students. This didactic process usually continues on the same way during the semester, without real evaluation of students' comprehension of the lectures through frequent formative assessment practices. Although at universities in the USA midterm exams and homework assignment are more common, the open-loop lecturing style, without real formative assessment during the semester is very common at most European universities. As a consequence, students would be unlikely to voluntarily reflect on the lectures. This results in poor comprehension of the learning outcomes, as well as increased cognitive load along the semester when the lecture content becomes harder and more dependent on the taught material during the previous lectures.

Recent pedagogical research has increasingly emphasized the important role of enriching teaching with formative assessment practices and providing the students with more feedback. In its national student survey in 2005 and 2006, the Higher Education Funding Council for England (HEFCE) [1] has found that UK students are unsatisfied with feedback and assessment practices during the semester. In particular students thought that they did not receive enough formative feedback about their actual learning level. Pedagogical research indicates that giving feedback is the most effective method teachers can use to foster and maintain student learning [1] and emphasizes that feedback must be provided quickly without delay.

Feedback is also the most important principle in Systems and Control Theory. In technical systems, it is well established that feedback may lead to improved robustness, disturbance rejection, stability, and reference tracking [2]. Hence, control engineers always aim to close the loop in their engineering designs. In an analogous way, formative assessment is a pedagogical approach for feeding the students useful information to bridge the gap in their learning process between the learning objectives and the actual achieved learning level [3]. In other words, formative assessment is a way of assisting the transformation of teaching and learning from open-loop to closed-loop structure by providing the students more feedback about their performance. Recently this methodology has received attention and has proved a positive impact on students learning and retention [4]. Case studies and approaches for delivering formative assessment can be found in [3].

This paper proposes mathematical models for open-loop and closed-loop lecturing. The models are used to analyze the two lecturing styles. Simulation results provide evidence of the superiority of the closed-loop lecturing mode compared open-loop lectures.

\section{STATE SPACE MODEl OF OPEN-LOOP LeCTURING}

Conceptual models are widely used for representing pedagogical processes. Despite their many advantages, conceptual models have limitations. For example, they do not provide a mathematical representation of the pedagogical process. Thus, the dynamic analysis of the lecturing system is not possible based on conceptual models. However, mathematical modeling itself is not a trivial task. In control engineering problems about $80 \%$ of the required effort for the project is usually devoted to mathematical modeling of the physical system. In the case of the lecturing process, which involves humans in the loop, the mathematical modeling would be more complicated than for technical systems. However, we draw on the generic approach used in the modeling of complex technical systems for control engineering purposes, which considers identifying simplified 


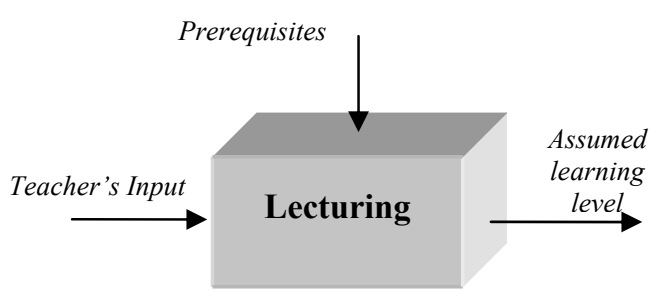

FIGURE 1

OPEN LOOP LECTURING.

models that capture the most important aspects of the system.

It is the case that the majority of university courses in higher education are taught in an open-loop mode. In the open-loop lecturing, the teacher keeps delivering material in the lectures from the semester beginning until the end without giving attention to the students' actual learning and without taking any measurements of this learning during the semester. A single measurement will take place at the end of the semester when the students take the final exam. This sort of measurement is called summative assessment. Figure 1 shows a block diagram of the open-loop lecturing.

In this open loop lecturing model, the teacher assumes that they increase the students knowledge during their lectures along the semester just by the fact the students progressively accumulated information lecture after lecture. The process of information accumulation by the teacher can be aggregated, lumped, and modeled by an integral action. Integration is the mathematical representation of an accumulating physical phenomenon such as filling a tank or changing a capacity. In this process of integration (or accumulation), teachers construct knowledge over the students previous knowledge (the prerequisite), the speed of accumulation or teaching (the slope of the assumed learning curve) is a factor determined by the teacher and it is the teacher's input to the process. This allows us to model the open-loop lecturing, or the knowledge construction during a lecture in state space form as follows:

$$
\frac{d x}{d t}=a \times u
$$

where $x$ represents the state space variable expressing the accumulated knowledge so far, $u$ is the teacher's input determining the speed of knowledge construction (in other words, the teaching speed), $a$ is a constant that differs from one course to another or from one lecture to another, this constant represents the students presumed capability to learn by the teacher.

Considering, for example, a five credit module; according to the European Credit Transfer System (ECTS) this will consist of 10-15 theoretical lectures. In many cases the lectures are a series of continua where each one depends on the previous one and aims to accumulate extra information over the previous one. This is specially the case in many undergraduate courses in engineering and science degrees. Hence we can consider the module lecturing as a
Session F1C

process of information accumulation by which the students are assumed to be continuously increasing their knowledge.

A course that is composed of (n) lectures taught in open loop mode can be then modeled as a series of (n) cascaded integrators as given in system (1), Figure 2 shows the block diagram representation. The complete state space representation of the assumed implemented knowledge of a module taught in open loop mode shown can be written as follows:

$$
\left[\begin{array}{c}
\dot{x}_{1} \\
\dot{x}_{2} \\
\vdots \\
\dot{x}_{n}
\end{array}\right]=\left[\begin{array}{cccc}
0 & 0 & \ldots & 0 \\
a_{2} & 0 & \ldots & 0 \\
0 & a_{3} & \ldots & 0 \\
\vdots & \vdots & & \vdots \\
0 & \ldots & a_{n} & 0
\end{array}\right]\left[\begin{array}{c}
x_{1} \\
x_{2} \\
\vdots \\
x_{n}
\end{array}\right]+\left[\begin{array}{c}
a_{1} \\
0 \\
\vdots \\
0
\end{array}\right] u
$$

The integrators represent the process of taught information accumulation. Each state $x_{i}$ represents the taught information so far up to lecture $i$. The model given by (2) represents the dynamical progress of the taught information by the lecturer. However, the actual students learning level would not be identical to the amount of taught information so far as represented in model (2). For instance, students may not have the presumed course prerequisite. The comprehension level differs significantly from one student to another student, and different disturbances on a student along the course could deviate the presumed learning curve from one lecture to another.

More importantly, since revision and reflection is not emphasized in open loop lecturing mode, students will normally tend not to practice them voluntarily, and this will cause the students to forget what they heard in the lectures as the time evolves along the course period. Furthermore, constructivists such as Kolb considered that knowledge is barely constructed out of information if it is not practiced. Hence only hearing the lectures is barely enough for something to be learned from the lectures. When students hear the lecture, the information is mainly received and worked out in the short term memory, especially if this information is heard for the first time and does not imply linkage to the students' previous knowledge. The information processing cognitive model of memory functionality [7] implies that repetition is important for guaranteeing the transfer of information from the short term memory to the long term memory, and also for further fixing of the already transferred in the long term memory. Normally, the amount of information taught in the lecture in higher education is more than the average cognitive ability of the students. This implies extra cognitive load on a student's mind and reduces the amount of retention after the lectures. Studies showed that students' attention in a lecture drops significantly after the first15-20 minutes. This in turn decreases the amount of lecture retained information. Considering the previous reasons, modeling the actual learning level of students in the open loop lecturing mode will lead us to upgrade the model given by (2) and include the forgetting curve factor which was discovered by 


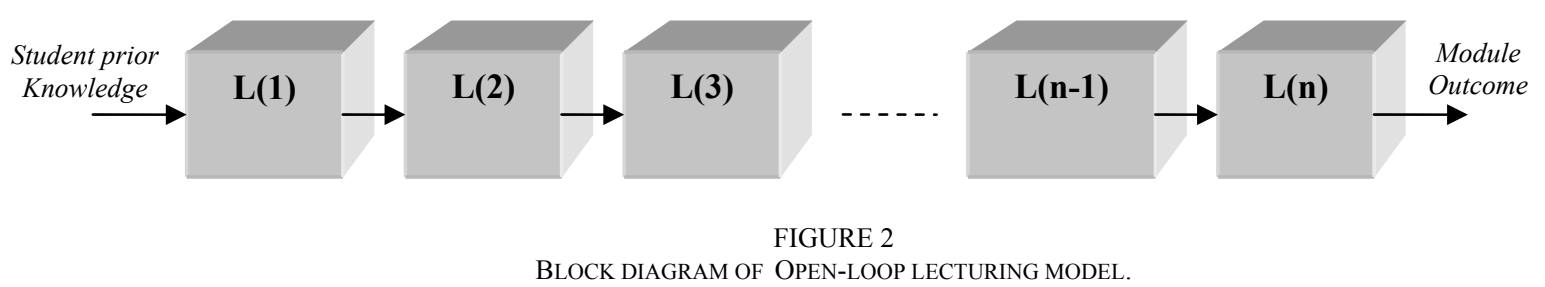

Ebbinghaus [8]. According to Ebbinghaus, humans tend to forget information in an exponential way. The forgetting curve is presented as an exponential decline in the retained information in the memory and is given by the formula:

$R_{\text {inf }}=e^{-a t}$, where $a$ is the memory strength factor.

The exponential decay depends on the difficulty of the learned material, which is normally non trivial in engineering or science higher education lectures. It is also affected by stress and sleep level. Hence, the actual students learning model in open lecturing mode can be written as follows:

$$
\left[\begin{array}{c}
\dot{x}_{1} \\
\dot{x}_{2} \\
\vdots \\
\dot{x}_{n}
\end{array}\right]=\left[\begin{array}{cccc}
0 & 0 & \ldots & 0 \\
a_{2} & 0 & \ldots & 0 \\
0 & a_{3} & \ldots & 0 \\
\vdots & \vdots & & \vdots \\
0 & \ldots & a_{n} & 0
\end{array}\right]\left[\begin{array}{c}
x_{1} \\
x_{2} \\
\vdots \\
x_{n}
\end{array}\right] \times e^{-a t}+\left[\begin{array}{c}
a_{1} \\
0 \\
\vdots \\
0
\end{array}\right] x_{0}
$$

The total amount of learned material after finishing the module is typically what students have learned up to the last lecture, hence the state space model output can be written as follows:

$$
y=\left[\begin{array}{llll}
0 & 0 & \cdots & 1
\end{array}\right]_{1 \times n}\left[\begin{array}{c}
x_{1} \\
x_{2} \\
\cdots \\
x_{n}
\end{array}\right]_{n \times 1}
$$

Where $y$ represents the amount of learned knowledge by the course end. Due to the forgetting factor in the model given by (3) and (4), the students are barely retaining or learning in the open loop lecturing mode any information or knowledge unless they practice revision and reflection during the course period, or after the course finishes in their preparation for a course exam.

\section{State Space Model of Closed Loop Lecturing}

The open loop lecturing model strongly represents a teachercentered approach of learning which has been a source of frequent criticism from the constructivists. Constructivist pedagogy perceives learning as a process of knowledge construction done mainly by the students' themselves, it emphasizes the students immersion in experience, the importance of feedback, and reflection.

We propose another approach of lecturing for more effective teaching. We derive a so called closed loop

978-1-4244-1970-8/08/\$25.00 C2008 IEEE $38^{\text {th }}$ ASEE/IEEE Frontiers in Education Conference

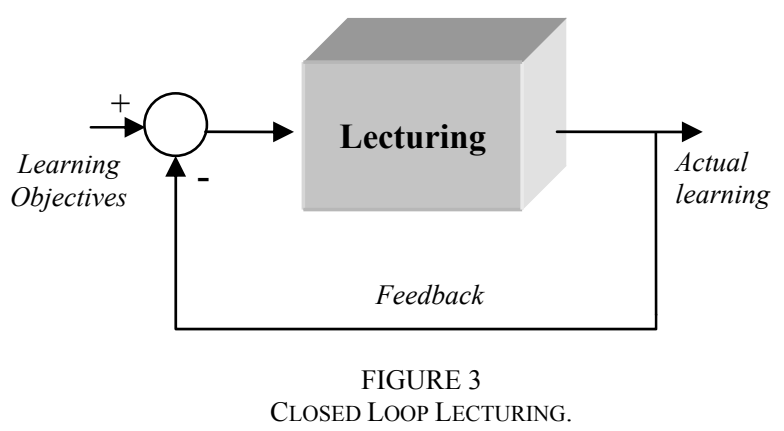

lecturing model based on theoretical background from cognitive science, pedagogy, and cybernetics. The main pillars of the model are fostering students' feedback and reflection during and after each knowledge accumulation stage, as well as, fostering the students' autonomy in the process of knowledge construction. The block diagram of the model is shown in Figure 3. The closed loop lecturing mode implies taking frequent formative assessment alongside the course as it progresses and continuously providing student feedback and reflection. In addition, the student is immersed in an active role rather than being passive, as is the normal case in traditional lectures (open loop lecturing). In the closed loop mode, students are made clear that they have to practice, that they are knowledge constructers, whilst the teacher's role is to coordinate their learning process. Furthermore, appropriate teaching and learning techniques should be followed to guarantee successful loop closure.

The major amount of information presented to students in the lecture is kept in the working memory, or short-term memory; such information will be forgotten unless it is transformed into the long term memory. Many cognitive science researchers have found that retention of information learned at school drops rapidly in the first few weeks after instruction, due to the forgetting factor explained earlier. However, whatever remaining retained information might be retained forever [9]. Such retained information is stored in the long-term memory. Repetition, reflection, and feedback are all factors that help transfer the taught information into the long term memory. Hence, effective teaching strategies that utilize these elements will mitigate the forgetting factor. According to constructivists, the immersion of a student in experiencing the taught information is an approach towards meaningful learning. Kolb considered the present grasp of information, or prehension [5], as a necessary condition but

October 22 - 25, 2008, Saratoga Springs, NY F1C-3 
Session F1C

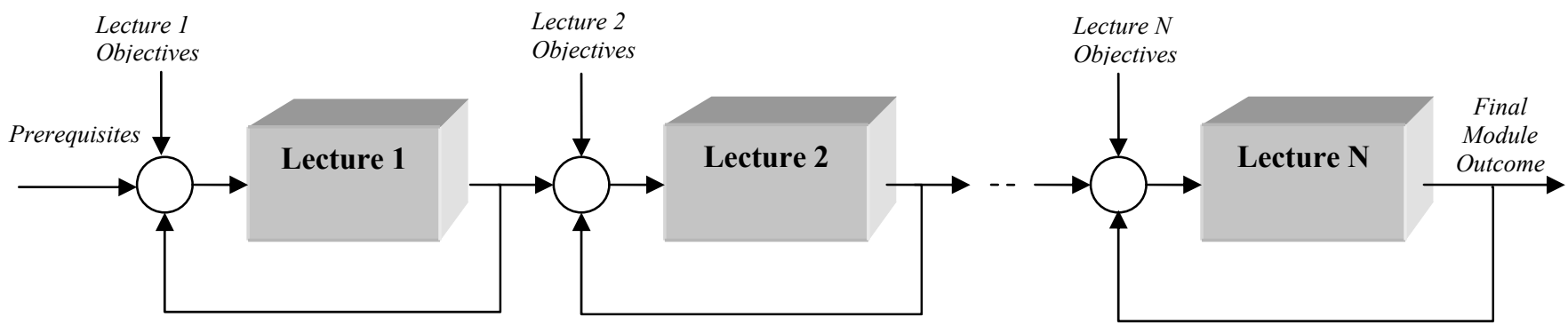

FIGURE 4

BLOCK DIAGRAM OF CLOSED LOOP LECTURING MODEL.

not enough for learning. Knowledge construction needs first knowledge or information to be grasped, but the meaningful construction will not take place unless the student immerses themselves in reflection and active experience of this understood information [5].

If knowledge construction is carried out by the student under teacher guidance during the lectures, and if this knowledge construction involved effective feedback and reflection, then we call it closed loop knowledge accumulation or constructivist knowledge construction. The aggregated state space model may then be given as:

$$
\frac{d x}{d t}=-\frac{1}{a} x+r
$$

where $r$ is the reference signal which means here a set of the lecture learning objectives, $x$ is the state space representing the dynamical state of the constructed knowledge so far, $a$ is a constant representing students ability on constructing knowledge, or in other words, the learning constant. The reference signal represents the set of information needed to be learned for the current lecture which normally the teacher will make clear for the students, i.e. clear lecture objectives. The student should be continuously assessed for his actual learning level and should be provided with an estimated measurement of the current gap between the learning objectives set and the actual learned ones. Such measurements of the actual learning level is formative assessment and can be achieved by the student themselves, the tutor, through peer assessment amongst students, or by using modern technologies. There exist market solutions for facilitating the formative assessment, such as electronic voting cards. However, is should be pointed out that the elements of a well designed course contributes to the facilitation of formative assessment.

Let us consider a module composed of 12 lectures. Each lecture aims at accumulating a defined amount of information and depends upon the material learnt in the previous lecture as a prerequisite to reach the new learning objectives. Let us assume that the module is designed in a way that develops effective student feedback and reflection on the taught lectures during the teaching period. Finally let us assume that the students put effort during the course period on learning, immersing themselves into active

\section{8-1-4244-1970-8/08/\$25.00 @2008 IEEE} $38^{\text {th }}$ ASEE/IEEE Frontiers in Education Conference learning and continuously practicing feedback and reflection. Thus, we may model the module lecture as sequence of cascaded closed loop integrators such as shown in Figure 4.

The complete state space model of the 12 lectures module can be written as follows:

$$
\begin{gathered}
\dot{X}=A_{c} X+B_{c} U \\
Y=C_{c} X
\end{gathered}
$$

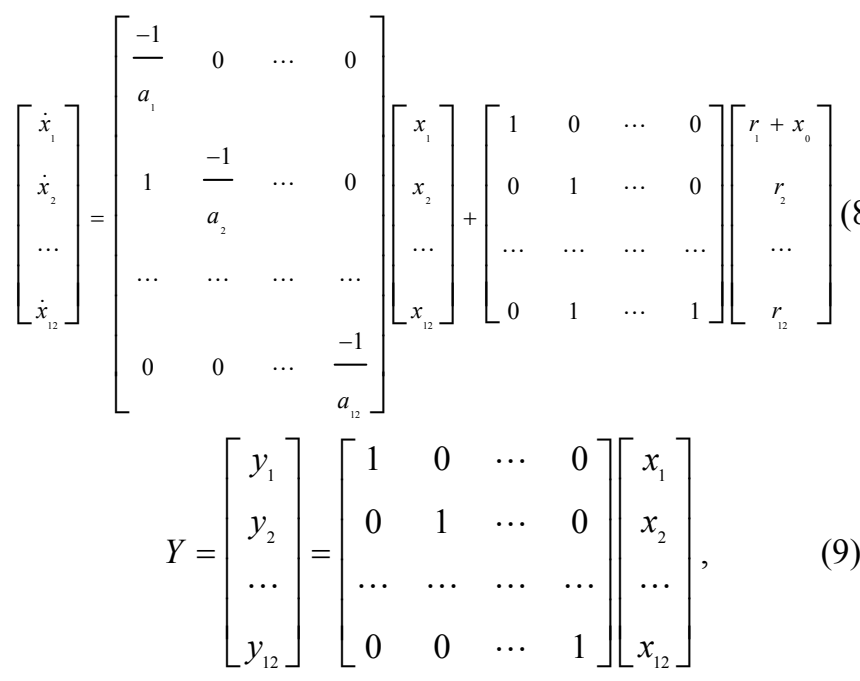

where $x_{i}, i=1,2, \ldots, 12$ are the dynamical internal states representing the constructed knowledge at each lecture, $y$ represents the measurements of the students actual learning level taken lecture by lecture, $r, i=1,2, \ldots, 12$ are the lectures learning objectives, $x_{0}$ is the course prerequisite. We notice here that the system matrix $A_{c}$ is a lower triangular, its Eigen values are represented by the main diameter:

$$
\lambda_{i}=\frac{-1}{a_{i}} \text { where } i=1,2,3 \ldots, 12 \text {. }
$$

All Eigen values are strictly negative, hence, the system is asymptotically stable, which means that in such model of lecturing, students are more likely to achieve the set learning objectives. However, in the open loop lecturing model, students are barely learning anything out of the lectures. Could this be a reason that many students drop attending the

October $22-25,2008$, Saratoga Springs, NY F1C-4 
lectures as they perceive them non useful. The controllability matrix of the system given in (6) and (7) is full rank which means that in a closed lecturing mode, the lecturer will be able to control the students progress in gaining knowledge through manipulating the learning objectives set.

\section{Robustness of Closed Loop Lecturing Mode}

The closed feedback loop shown in Figure 3 has an inherent robustness characteristic against model uncertainty; the uncertain model version of system given by (5) can be written as follows:

$$
\frac{d x}{d t}=-\frac{1}{a}(x+\Delta x)+r
$$

Where $\Delta x$ represent the uncertainty. Figure 5 shows the block diagram of the one lecture closed loop model with uncertainty. The model uncertainty may represent an uncertainty in one student's ability in learning, i.e. a different value of the parameter $1 / a$ from the nominal assumed value of the class, a weaker student than average can be modeled with an uncertainty term. The full state space model of a twelve lecture module with closed loop lecturing mode and uncertainty of students' ability on learning can be written as follows:

$$
\dot{X}=A_{c}(X+\Delta X)+B_{c} U
$$

While the output can be written as follows:

$$
Y=C_{c}(X+\Delta X)
$$

Where $A_{c}, B_{c}$ are as given in (8) and (9), and $\Delta X=\left[\begin{array}{c}\Delta x_{1} \\ \Delta x_{2} \\ \cdots \\ \Delta x_{12}\end{array}\right]$

To show the robustness characteristic of a closed feedback in an accumulating system, we simulate the nominal system given by equations (8) and (9) and compare it with the simulation of a $50 \%$ weaker student by setting $\Delta X_{i}=0.5 X_{i}$ in the uncertain model given by (11) and (12). Figure 6 shows the simulations results; we notice that in spite of the half capability of the weaker student, they could achieve close performance from the nominal students' average by developing feedback and reflection practices. By the end of the module, the weak student was only about $10 \%$ behind the class average.

\section{Conclusions}

This analytical study showed that in the open loop mode, by the end of the module students final learning outcomes tend to be zero due to the lack of practice, feedback, reflection and hence a higher exponential decay of the forgetting factor. Therefore, students do not benefit from the open loop lecturing mode. On the other hand, the closed loop lecturing mode has many advantages. It develops constructivist learning, feedback and reflection, and the immersion of students in active learning. The set learning objectives in the closed loop lecturing model are achievable due to the asymptotic stable nature of the model. A very important characteristic of the close loop lecturing model is that it represents a way of closing the gap between weak and nominal students. One of the main distinguishing characters

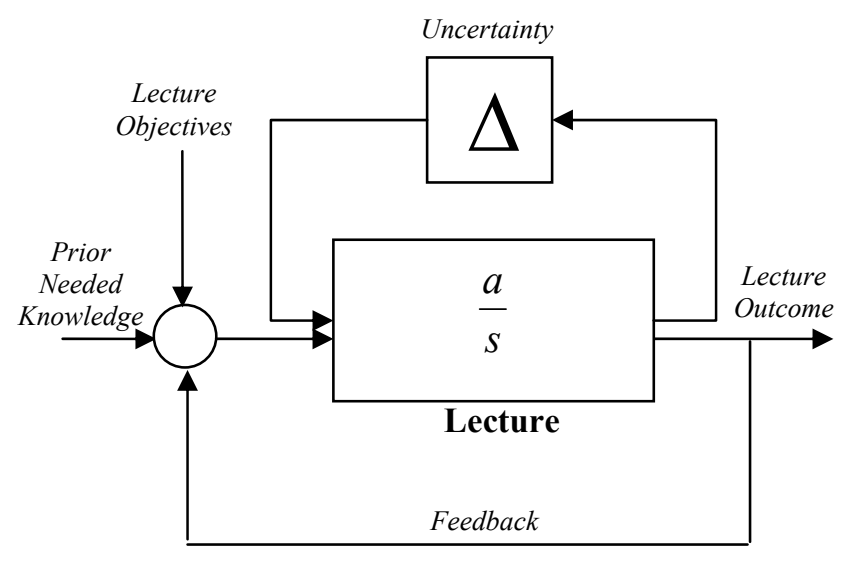

FIGURE 5

CLOSED LOOP LECTURE WITH STUDENT'S UNCERTAINTY

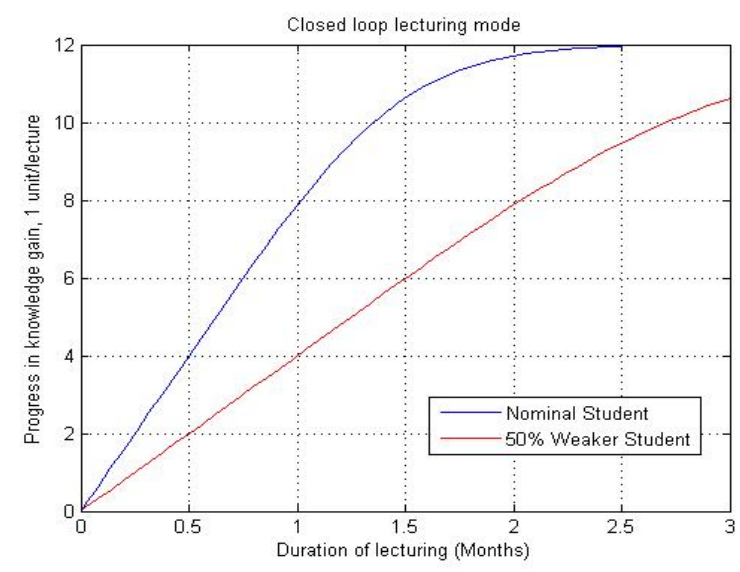

FIGURE 6

SIMULATION OF NOMINAL VS. WEAK STUDENT PERFORMANCE

of the closed loop lecturing model studied so far in contrast with the open loop model is the absence of the forgetting term. The continuous process of reflection and feedback will foster students' repetition of the material need to be learnt. This repetition will help in transferring this information to the long term memory. The active immersion of students in experiential learning of taught material will lead to the dynamic transformation of the taught information into meaningful mental models. Further research is needed to answer important questions, such as how to implement the continuous feedback loop in teaching, or what practices should be used. Some initial results have been achieved by using remote voting systems with multiple choice questions during the lecture, however additional research is needed to provide quantitative evidence of the theoretical concepts presented in the paper.

October $22-25,2008$, Saratoga Springs, NY $38^{\text {th }}$ ASEE/IEEE Frontiers in Education Conference F1C-5 


\section{REFERENCES}

[1] Race, P, "Making Learning Happen", Sage (Paul Chapman) Publications 2005.

[2] Goodwin, GC, Graebe, SF, "Control System Design", Prentice Hall 2001.

[3] Juwah, C, Macfarlane-Dick, D, Matthew, B, Nicol, D, Ross, D, and Smith, B, "Enhancing student learning through effective formative feedback", The Higher Education Academy Generic Centre Publications, 2004.

[4] Black, P, "Assessment and feedback in science education", Studies in Educational Evaluation, 21, 1995, pp. 257-279.

[5] Kolb, DA, "Experiential learning: experience as the source of learning and development", Prentice-Hall, 1984.

[6] Thomas, JW, San Rafael, CA, “A review of research on project-based learning", Autodesk Foundation, March, 2000.

[7] Atkinson, R C, Shiffrin, R M, "Human Memory: A proposed system and its component processes", In K. Spence \& J. Spence (Eds.), The psychology of learning and motivation, vol. 2. New York: Academic Press, 1968.

[8] Baddeley, AD, "Essentials of human memory", Psychology Press, Hove, 1999.

[9] Bahrick, HP, Hall, LK, "Lifetime Maintenance of High School Mathematics Content", Journal of experimental psychology: general, 120, 1, 1991, pp.20-33.

\section{AUTHORS INFORMATION}

Mahmoud Abdulwahed, Engineering education researcher, Engineering Center of Excellence in Teaching and Learning and the Chemical Engineering Department, Loughborough University, United Kingdom, m.abdulwahed@lboro.ac.uk.

Zoltan K Nagy, Senior lecturer, member IEEE, Chemical Engineering Department, Loughborough University, United Kingdom, z.k.nagy@lboro.ac.uk.

Richard Blanchard, Lecturer, Electronic and Electrical Engineering Department, Loughborough University, r.e.blanchard@lboro.ac.uk 